\title{
Parent-adolescent relationship quality as a predictor of leaving home
}

\author{
Rengin Işık Akın*, Linda D. Breeman, Wim Meeus, Susan Branje \\ Faculty of Social and Behavioral Studies, Utrecht University, Heidelberglaan 1, 80125, 3508, TC Utrecht, the Netherlands
}

\section{A R T I C L E I N F O}

\section{Keywords:}

Leaving home

Parent-adolescent relationship

Life transitions

Survival analysis

\begin{abstract}
A B S T R A C T
Introduction: Leaving home is a significant life transition that effects both emerging adults and their families. The age of leaving home has been increasing across industrialized societies, and children remain dependent on their parents for a longer time. The present study investigated the association between parent-adolescent relationships and timing of leaving home over a timespan of six years: From middle adolescence to emerging adulthood.

Methods: Data came from three cohorts of two longitudinal studies in the Netherlands $(\mathrm{N}=1100)$. At the start of the study, participants had a mean age of $16.41(S D=.71)$, and approximately half of them $(n=547)$ were male. Adolescents completed questionnaires on parent-adolescent relationship quality. The impact of positive and negative relationship characteristics on timing of leaving home were examined separately for mothers and fathers.

Results: Survival analysis results showed that higher levels of mother's and father's warmth, and higher levels of power attributed to father, but not mother, predicted later timing of leaving home. Higher levels of parental autonomy support predicted earlier timing of leaving home. Conflict with parents was not associated with timing of leaving home, except in the fatherdaughter relationship. Only, the effect of parental warmth on timing of leaving home remained robust when controlling for age, gender, education level, and SES.

Conclusions: Our findings indicate that certain parent-adolescent relationship characteristics contribute to the increase in age of leaving home. Parents may be able to prepare their children for a self-sufficient living by balancing warmth and autonomy support they provide during adolescence.
\end{abstract}

Leaving home is a significant life transition since it clearly marks the individuation process for emerging adults (Arnett, 2004). While the age of leaving home has been increasing across industrialized countries, it also shows great diversity (Seiffge-Krenke, 2013), and its determinants are multifaceted. Studies have reported associations between leaving home and cultural background (Kleinepier \& De Valk, 2017), gender (Blaauboer \& Mulder, 2010), family resources (De Jong Gierveld, Liefbroer, \& Beekink, 1991), and other developmental tasks associated with emerging adulthood (Seiffge-Krenke, 2009, 2010), but only few looked at the relation between leaving home and parent-adolescent relationship quality.

From a life-course perspective, leaving home is a developmental task that affects not only the emerging adults but the whole family. According to the 'linked lives' principle of this perspective, individuals in a family unit are interdependent (Elder, Johnson, \& Crosnoe, 2003), and leaving home is a family decision (Goldscheider \& Goldscheider, 1998). The timing of leaving home is therefore expected to be closely associated with parent-adolescent relationship quality. Little research, however, examined how earlier parent-

\footnotetext{
${ }^{*}$ Corresponding author.

E-mail address: r.isik-akin@uu.nl (R.I. Akın).
} 
adolescent relationship quality affected the leaving home process. The studies with a prospective design (De Jong Gierveld et al., 1991; Seiffge-Krenke, 2006; South \& Lei, 2015) revealed adolescents who have a positive parent-child relationship are more likely to leave home later. However, most of these studies only focused on the overall relationship quality, and did not investigate the relationship with mothers and fathers separately. Some had a small sample size (e.g. Seiffge-Krenke, 2006) and only examined relationship quality after the child was 18 years old (e.g. De Jong Gierveld et al., 1991). The current research aimed to investigate whether parent-adolescent relationship characteristics predict the timing of leaving home during the transition from adolescence to emerging adulthood, and to assess positive and negative aspects of relationship quality separately for mothers and fathers, covering six years from middle adolescence to the early years of emerging adulthood, using a relatively large sample size.

\section{Extended period of leaving home}

Due to socioeconomic changes within the past few decades (i.e., extended years in education, higher unemployment rates, increases in rent prices, and changes in welfare systems) (Goldscheider \& Goldscheider, 1994), emerging adults remain dependent on their parents for a longer time (Kins, De Mol, \& Beyers, 2013). For instance, for 18 to 34-year-olds residing in the United States, living with parents has surpassed any other form of living within the past century (Fry, 2016). Similarly, in Europe, almost half of the individuals aged between 18 and 34 are living with at least one parent (Choroszewicz \& Wolff, 2010). However, there are also regional/cultural differences. For instance, in Southern and Eastern Europe, a significantly higher percentage of young individuals between the ages of 24 and 29 continues to live at home, compared to Northern Europe (Choroszewicz \& Wolff, 2010). This difference is considered to be due to a stronger welfare system and individualistic societal norms in North European countries (Billari \& Liefbroer, 2007), versus stronger family ties and more traditional norms in Southern and Eastern European countries (Crocetti \& Meeus, 2014).

Demographic characteristics such as gender and family socioeconomic status (SES) are also related to the timing of leaving home. Generally, women leave home two-to-three years earlier than men (Buck \& Scott, 1993; Kleinepier \& De Valk, 2017), yet some studies did not find any gender differences (e.g. Seiffge-Krenke, 2006). One possible explanation for this difference is that women enter stable, intimate partnerships earlier than men (Buck \& Scott, 1993; Kleinepier \& De Valk, 2017). Thus, not only the timing but also reasons for leaving home may vary by gender and related societal norms. Regarding SES, higher levels are associated with earlier timing of leaving home (De Jong Gierveld et al., 1991; De Marco \& Berzin, 2018). However, a cross-national study in Europe found when countries were analyzed separately, family SES was no longer a significant predictor of leaving home (Le Blanc \& Wolff, 2006).

\subsection{Home leaving trends among Dutch emerging adults}

In line with recent trends across many countries, life transitions associated with adulthood - such as leaving home, finishing education, and starting employment - are occurring at a later age in the Netherlands compared to a decade ago (CBS, 2019). As half of emerging adults (ages 20-24) continue with higher education (Coyette, Fiasse, Johansson, Montaigne, \& Strandell, 2015) and stay in education longer compared to 2008 (CBS, 2019), the other half is assumed to be working or in training, given that the Netherlands has the lowest rate (4\%) of youth not in employment, education, or training (NEET) in Europe (CBS, 2018), and compulsory military service has been suspended for the past 20 years. The mean age of leaving home has increased from 23.6 to 24.6 years from 2006 to 2016 (CBS, 2016). Women continue to show a pattern of earlier home leaving compared to men, but this gender gap has shrunk within the past decade (CBS, 2019).

\section{Parent-adolescent relationship quality and leaving home}

In adolescence, parent-child relationships gradually become more egalitarian (De Goede, Branje, Delsing, \& Meeus, 2009). In line with the changing needs of adolescents, parents tend to adjust their parenting practices by relinquishing some power (Aquilino, 2006), but these changes often lead to a temporary increase in conflict, and a decline in support and closeness in parent-adolescent relationships (De Goede et al., 2009). Before adolescents usually leave home, conflict with parents and parental power further decline, autonomy support continues to increase (Seiffge-Krenke, 2006), and parental support stabilizes for boys and increases for girls (De Goede et al., 2009). From autonomy-relatedness perspective (Grotevant \& Cooper, 1986), adolescents optimally develop their autonomy when they maintain connectedness to their parents. Studies showed adolescents consulted their parents for important decisions, but they also had ambivalent feelings about being independent and remaining close to them (Kins et al., 2013). Yet the balance between autonomy and relatedness may be tested once again during the leaving home process (Seiffge-Krenke, 2006). For instance, adolescents who perceived lower levels of autonomy and relatedness experienced more difficulty in separating from their parents in emerging adulthood (O'Connor, Allen, Bell, \& Hauser, 1996). Parents with higher levels of separation anxiety used more psychological control to ensure their children stayed close to them (Kins, Soenens, \& Beyers, 2013). Thus, leaving home and transition to adulthood might be easier when adolescents and parents establish a healthy balance between autonomy and relatedness.

Overall, findings show adolescents with a positive parental relationship are more likely to stay at home for a longer time (Bucx \& Van Wel, 2008; Seiffge-Krenke, 2006). This association is stronger for women than for men (Blaauboer \& Mulder, 2010), and also for the relationship with mothers than with fathers (South \& Lei, 2015). As for specific relationship characteristics, young individuals who left home later reported higher levels of parental support (Seiffge-Krenke, 2009, 2010), lower levels of conflict, but also lower levels of support for independence during adolescence (Seiffge-Krenke, 2006), compared to those who already moved out. These results suggest that parent-adolescent relationship quality plays an important role in the leaving home process. However, it is still 
unclear how specific characteristics of adolescents' relationship with mothers and fathers affect the timing of leaving home, and whether gender moderates these effects. Thus, this study will focus on four essential relationship characteristics (warmth, autonomy support, conflict, and power), and examine their impact on the timing of leaving home separately for mothers and fathers.

\section{The present study}

The first goal of this study was to investigate whether the timing of leaving home depends on gender, education level, and SES, in a longitudinal sample following adolescents into emerging adulthood over a period of six years. We expected that women, adolescents with higher levels of education, and from high SES families, will leave home earlier compared to men, adolescents with lower levels of education and from low SES families. The second goal was to investigate the association between timing of leaving home and relationship quality with mothers and fathers. Based on previous research, we expected that paternal warmth would be related to later timing of leaving home, while autonomy support, conflict and power would be related to earlier timing of leaving home. We chose to focus on relationship qualities during middle adolescence, to be able to assess relationship quality at the same age for those who leave the parental home early versus late. We used survival analysis' hazard approach to obtain good estimates of the timing of leaving home by including censored data (i.e. those who did not yet left home) rather than categorizing timing of leaving home as early, on-time and late home leaving as in previous studies (Seiffge-Krenke, 2009, 2010, 2006; Tang, 1997).

\section{Method}

\subsection{Participants and procedure}

A multiple-cohort approach was used to investigate the association between parent-adolescent relationship quality and timing of leaving home using data from three cohorts of two longitudinal research projects in The Netherlands: Conflict and Management of Relationships (CONAMORE; Meeus et al., 2004), and Research on Adolescent Development and Relationship (RADAR). We included adolescent participants starting from the measurement wave in which they were approximately 16 years old. Overall, the study examined five waves of data collection over a period of six years, from ages 16 to 22 .

All cohorts included the same variables with annual measurements, except the last two waves of the RADAR cohorts, which had a one and a half year, and a two-year time gap in between measurements. At Time 1 of the present study, the CONAMORE cohort (CONAMORE; $n=390$, Time1 $=2001$ ) had an average age of $16.68(S D=.80)$. The older cohort of RADAR (RADAR-old; $n=244$, Time $1=2005)$ had an average age of $16.73(S D=.60)$, and the RADAR-young cohort $(n=497$, Time $1=2010)$ had an average age of $16.02(S D=.45)$ which was significantly lower compared to the first two cohorts $(p<.001)$. The RADAR-young had more male adolescents (56.9\%) compared to both CONAMORE (43.3\%) and RADAR-old (46.0\%). The RADAR-old had more adolescents with higher levels of education (49.1\%) compared to both CONAMORE (38.1\%) and RADAR-young (35.7\%). In parallel, the RADAR-old also had more adolescents coming from high SES families (84.5\%) compared to both CONAMORE (66.8\%) and RADAR-young $(68.5 \%)$.

Thirty-one participants had no available parent-adolescent relationship data, and thus they were excluded. These participants were not different from the remaining sample with respect to gender and age. The total sample included 1100 adolescents at Time 1 with a mean age of $16.41(S D=.71)$. Half of the participants $(n=547,50 \%)$ were male. The majority of the sample was Dutch (94.6\%) and ethnic minority adolescents (3.2\%) were mostly from Surinam, Turkey, or Morocco. Two-thirds of the participants $(68.1 \%)$ came from families in which one or both parent(s) completed either high or academic level education. More than half of the adolescents (58.9\%) completed either low or medium levels of education throughout the study. At Time 1, most adolescents reported having intact families (81.6\%) and living with their parents (93.4\%).

Attrition analysis was conducted by comparing those who had dropped out by Time $5(n=159)$ to those who were still participating after four waves $(n=941)$. The two groups did not differ by gender, age at Time 1 , and any of the parent-adolescent relationship qualities. However, those who dropped out of the study were more often from low-mid SES families ( $p<.001)$ and had lower levels of education $(p<.001)$, than those who continued to participate. Little's Missing Completely at Random (MCAR) test showed that values were missing at random $\left(\chi^{2}(45)=41.63, p>.05\right)$.

Written informed consent was obtained from all respondents who agreed to participate. For the CONAMORE and RADAR-old cohorts, high schools in the province of Utrecht, and for the RADAR-young cohort, elementary schools in the western and central regions of the Netherlands were approached. Adolescents and their parents were invited to participate via informational letters. Adolescents completed the questionnaires either at school or during home visits, and parents completed them at home. In the CONAMORE study, adolescents received $€ 10$ at each measurement as monetary compensation. In the RADAR study, adolescents received $€ 20$ at each home visit. The CONAMORE study was approved by the review board of the Institute for the Study of Education and Human Development, and the RADAR study was approved by the ethical-medical committee of University Medical Centre Utrecht, the Netherlands.

\subsection{Measures}

\subsubsection{Parent-adolescent relationship quality}

Perceived parent-adolescent relationship quality at Time 1 was assessed by adolescents' reports on warmth, conflict, and power with the Dutch-adapted version of the Network of Relationship Inventory-short form (NRI; Furman \& Buhrmester, 1985) and 
autonomy support with the Balanced Relatedness subscale from Shulman's Intimacy Scale (Shulman, Laursen, Kalman, \& Karpovsky, 1997). All three subscales of the NRI were measured on a 5-point Likert scale ranging from $1=$ a little or not at all to $5=$ more is not possible. Warmth was measured using the eight items of the Support subscale and had an internal consistency of 0.86 . An example item is "How much does your mother really care about you". The Conflict and Power scales each had six items, and had an internal consistency of 0.87 and 0.80 respectively. Example items are "How much do you and your mother argue with each other?" and "To what extent is your mother the boss in your relationship?" The Balanced Relatedness scale was based on a 4-point scale ranging from $1=$ not true to $4=$ very true. The scale included seven items, such as "My mother respects my ideas", and had an internal consistency of 0.89 . For each subscale, higher scores represented higher levels of the relationship quality.

\subsubsection{Living situation}

At each wave, participants were asked about their current living situation using a single question "Who do you live with at the moment?" Answers were dummy coded into two categories: $0=$ continuing to live with parents, $1=$ moved out. Answers such as living alone, with a partner/roommate/relative, in a student dorm, and abroad were all recoded as moved out.

\subsubsection{Covariates}

Adolescent's age at Time 1 , gender $(0=$ male, $1=$ female), highest education level, and family SES were selected as study covariates. Adolescent's education level was recorded at each measurement wave, and the education outcome variable was determined by the highest education level across all waves using a dummy variable: $0=10 \mathrm{w} / \mathrm{middle}$ (i.e., prevocational or vocational education) and $1=$ high/academic (i.e., higher professional education, university). SES was assessed by a single question and highest education levels of each parent were combined into a dummy variable as an indicator of SES: $(0=10 w / m i d d l e, ~ 1=h i g h / a c a d e m i c)$.

\subsection{Data analysis}

A survival analysis was performed because not all of the participants had left home during the course of the study. Survival analysis considers both time to an event (i.e., timing of leaving home) and event status (i.e. left home yes/no). Time until leaving home was determined by the years after the first measurement wave until the participant left home (ranging from 0 to 6 years), and event status was determined by whether the participant left home at any point during the study $(0=$ continuing to live with parents, 1 = moved out). First, a baseline hazard model was estimated in SPSS 24.0 to determine the timing of leaving home. Second, this baseline model was tested separately for adolescent's gender, education level, and SES using a Kaplan-Meier analysis. Finally, to answer our main research question, the Cox Proportional Hazard Model was utilized to assess the effect of the predictors on the probability of the event. The hazard model provides hazard ratios (HR) for each predictor which show the likelihood of an event (i.e., leaving home) for someone surviving up to a certain time point (Güçlï; Çetinkaya, 2015). First, all four relationship qualities were added into the model together. Second, adolescent's age, gender, education level, and SES were included as covariates. In the third and final step, interaction effects between gender and parent-adolescent relationship variables were included. All models were run separately for mothers and fathers. The proportional hazards assumption was met for all predictors.

\section{Results}

\subsection{Descriptives and measurement invariance}

Descriptive statistics and correlations for all parent-adolescent relationship variables are reported in Table 1. All mother-adolescent and father-adolescent relationship qualities at Time 1 were significantly correlated with each other $(p<.01)$, except for paternal warmth and paternal/maternal power. Variance inflation factor (VIF) values showed no multicollinearity among the parentadolescent relationship variables.

Relationship constructs for mothers and fathers were tested for measurement invariance, taking into account the non-

Table 1

Descriptive statistics and correlations for parent-child relationship qualities at Time-1.

\begin{tabular}{|c|c|c|c|c|c|c|c|c|c|}
\hline Variable & $M(S D)$ & 1 & 2 & 3 & 4 & 5 & 6 & 7 & 8 \\
\hline \multicolumn{10}{|l|}{ Mother } \\
\hline 1. Warmth & 3.57 (.65) & - & & & & & & & \\
\hline 2. Conflict & 1.67 (.69) & $-.31 *$ & - & & & & & & \\
\hline 3. Power & $2.54(.71)$ & $.13^{*}$ & $.24 *$ & - & & & & & \\
\hline 4. Aut. sup. & $3.23(.46)$ & $.55^{*}$ & $-.37 *$ & $-.15^{*}$ & - & & & & \\
\hline \multicolumn{10}{|l|}{ Father } \\
\hline 5. Warmth & $3.34(.68)$ & $.43^{*}$ & $-.17^{*}$ & .01 & $.27^{*}$ & - & & & \\
\hline 6. Conflict & $1.64(.69)$ & $-.11^{*}$ & $.34 *$ & $.11^{*}$ & $-.16^{*}$ & $-.34 *$ & - & & \\
\hline 7. Power & $2.50(.73)$ & $.09 *$ & $.12^{*}$ & $.56 *$ & $-.11 *$ & .01 & $.23^{*}$ & - & \\
\hline 8. Aut. sup. & $3.19(.47)$ & $.41^{*}$ & $-.18^{*}$ & $-.10^{*}$ & $.61 *$ & $.47^{*}$ & $-.42^{*}$ & $-.13^{*}$ & - \\
\hline
\end{tabular}

Note. Aut. sup. = autonomy support.

$* p<.01$. 


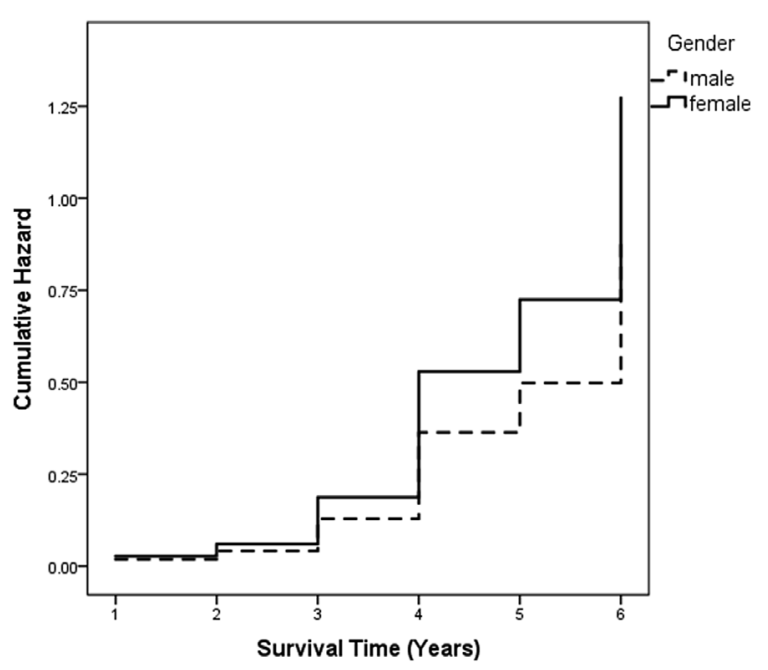

Fig. 1. Baseline hazard model for men and women leaving home across the six years of the study.

independence of the data. For Conflict, Power, and Autonomy Support, both metric and scalar invariance models did not lead to worse fit beyond the recommended thresholds ( $\leq .010$ between two successive models; Little, 2013). However for Warmth, only metric invariance was established (see Appendix). Further analyses on Warmth revealed that one item's intercept differed for mothers and fathers. Given that mother and father constructs were tested in separate models and their means were not compared, metric invariance was sufficient for comparing strength of associations.

\subsection{Timing of leaving home}

During the course of the study, half of the participants (49.5\%) had left home at least once, and mean age of leaving home for those who left was 20.29 ( $S D=2.07$ ). However, using the baseline hazard model including the censored data (i.e., adolescents who still lived at their parental home after five waves), leaving home was estimated as 4.97 years after the baseline measurement $(S D=0.04 ; 95 \%$ confidence interval [CI] 4.89 to 5.05) which, added to the mean age at Time 1, resulted in an estimated mean age of 21.38 years for leaving home. During the early years of the study, only a few participants left home, but especially around the fourth year (when participants were approximately 20 years old), the cumulative probability of leaving home increased (see Fig. 1).

The baseline hazard function of leaving home differed by adolescents' gender, education level, and SES. Women left home significantly earlier than men $\left(\chi^{2}(1)=23.56, p<.001\right)$. Adolescents from families with higher levels of SES left home earlier compared to those from families with lower levels of SES $\left(\chi^{2}(1)=46.42, p<.001\right)$. Adolescents with higher levels of education left home earlier than those who had lower levels of education $\left(\chi^{2}(1)=123.78, p<.001\right)$.

Table 2

Coefficients and 95\% confidence intervals for cox regression models of adolescent-mother relationship quality predicting leaving home.

\begin{tabular}{|c|c|c|c|c|c|c|c|c|c|c|c|c|}
\hline \multirow[t]{2}{*}{ Variable } & \multicolumn{4}{|c|}{ Model 1} & \multicolumn{4}{|c|}{ Model 2} & \multicolumn{4}{|c|}{ Model 3} \\
\hline & $b$ & HR & $p$ & $95 \% \mathrm{CI}$ & $b$ & HR & $p$ & $95 \% \mathrm{CI}$ & $b$ & HR & $p$ & $95 \% \mathrm{CI}$ \\
\hline Warmth & -.25 & .78 & .00 & {$[.65, .92]$} & -.22 & .80 & .02 & {$[.67, .97]$} & -.27 & .76 & .05 & {$[.58,1.00]$} \\
\hline Conflict & .09 & 1.09 & .22 & {$[95,1.25]$} & -.01 & .99 & .87 & {$[.86,1.14]$} & .02 & 1.02 & .86 & {$[.82,1.27]$} \\
\hline Power & -.13 & .88 & .06 & {$[.77,1.00]$} & -.09 & .91 & .20 & {$[.80,1.05]$} & -.07 & .93 & .50 & {$[.76,1.15]$} \\
\hline Aut. sup. & .42 & 1.52 & .00 & {$[1.18,1.96]$} & .19 & 1.21 & .15 & {$[.93,1.58]$} & .29 & 1.33 & .15 & {$[.89,1.97]$} \\
\hline Age & & & & & .18 & 1.20 & .00 & {$[1.06,1.35]$} & .19 & 1.21 & .00 & {$[1.07,1.36]$} \\
\hline Gender & & & & & .49 & 1.64 & .00 & {$[1.37,1.96]$} & .50 & 1.65 & .00 & {$[1.38,1.98]$} \\
\hline Edu. & & & & & .74 & 2.09 & .00 & {$[1.73,2.52]$} & .74 & 2.09 & .00 & {$[1.73,2.53]$} \\
\hline SES & & & & & .46 & 1.58 & .00 & {$[1.24,2.01]$} & .46 & 1.58 & .00 & {$[1.24,2.01]$} \\
\hline Warmth*Gender & & & & & & & & & .09 & 1.09 & .64 & {$[.75,1.58]$} \\
\hline Conflict*Gender & & & & & & & & & -.05 & .95 & .76 & {$[.71,1.28]$} \\
\hline Power*Gender & & & & & & & & & -.03 & .97 & .82 & {$[.74,1.27]$} \\
\hline Aut. sup. ${ }^{*}$ Gender & & & & & & & & & -.16 & .85 & .54 & {$[.50,1.43]$} \\
\hline
\end{tabular}

Note. $\mathrm{HR}=$ hazard ratio $\left(\mathrm{Exp}_{\mathrm{b}}\right)$; Aut. sup. = autonomy support; Edu. = education; SES = socioeconomic status. $p<.05$ are in boldface. 
Table 3

Coefficients and 95\% confidence intervals for cox regression models of adolescent-father relationship quality predicting leaving home.

\begin{tabular}{|c|c|c|c|c|c|c|c|c|c|c|c|c|}
\hline \multirow[t]{2}{*}{ Variable } & \multicolumn{4}{|c|}{ Model 1} & \multicolumn{4}{|c|}{ Model 2} & \multicolumn{4}{|c|}{ Model 3} \\
\hline & $b$ & $\mathrm{HR}$ & $p$ & $95 \% \mathrm{CI}$ & $b$ & HR & $p$ & $95 \% \mathrm{CI}$ & $b$ & HR & $p$ & $95 \% \mathrm{CI}$ \\
\hline Warmth & -.22 & .80 & .02 & {$[.66, .96]$} & -.19 & .83 & .05 & {$[.69,1.00]$} & -.25 & .78 & .08 & {$[.58,1.03]$} \\
\hline Conflict & .02 & 1.02 & .78 & {$[.87,1.19]$} & -.06 & .94 & .46 & {$[.80,1.10]$} & -.28 & .76 & .04 & {$[.58, .99]$} \\
\hline Power & -.14 & .87 & .04 & {$[.76, .99]$} & -.07 & .93 & .32 & {$[.82,1.07]$} & .04 & 1.04 & .71 & {$[.83,1.30]$} \\
\hline Aut. sup. & .34 & 1.40 & .01 & {$[1.09,1.80]$} & .05 & 1.05 & .70 & {$[.81,1.37]$} & .24 & 1.27 & .24 & {$[.85,1.88]$} \\
\hline Age & & & & & .23 & 1.25 & .00 & {$[1.11,1.41]$} & .22 & 1.25 & .00 & {$[1.11,1.40]$} \\
\hline Gender & & & & & .49 & 1.63 & .00 & {$[1.36,1.96]$} & .51 & 1.67 & .00 & {$[1.39,2.01]$} \\
\hline Edu. & & & & & .75 & 2.13 & .00 & {$[1.76,2.57]$} & .78 & 2.18 & .00 & {$[1.80,2.64]$} \\
\hline SES & & & & & .53 & 1.69 & .00 & {$[1.32,2.18]$} & .53 & 1.69 & .00 & {$[1.32,2.18]$} \\
\hline Warmth*Gender & & & & & & & & & .15 & 1.16 & .45 & {$[.79,1.70]$} \\
\hline Conflict* Gender & & & & & & & & & .34 & 1.41 & .04 & {$[1.01,1.97]$} \\
\hline Power*Gender & & & & & & & & & -.18 & .84 & .21 & {$[.63,1.11]$} \\
\hline Aut. sup. ${ }^{*}$ Gender & & & & & & & & & -.35 & .70 & .19 & {$[.42,1.18]$} \\
\hline
\end{tabular}

Note. $\mathrm{HR}=$ hazard ratio $\left(\operatorname{Exp}_{\mathrm{b}}\right) ;$ Aut. sup. $=$ autonomy support; Edu. $=$ education; $\mathrm{SES}=$ socioeconomic status. $p<.05$ are in boldface.

\subsection{Parent-adolescent relationship quality as a predictor of leaving home}

\subsubsection{Adolescent-mother relationship quality}

Three models regarding adolescent-mother relationship quality and leaving home were examined (see Table 2). In Model 1, warmth and autonomy support significantly predicted timing of leaving home. For every unit increase in maternal warmth, the likelihood of leaving home decreased by $22 \%(\mathrm{HR}=0.78, p=.004)$ and for every unit increase in maternal autonomy support, the likelihood of leaving home increased by $52 \%$ ( $\mathrm{HR}=1.52, p=.001)$. Conflict and power did not add to the prediction of the timing of leaving home. Covariates were added in the next step (Model 2) and only the effect of maternal warmth on leaving home remained significant. All demographic covariates significantly contributed to the model. In line with the earlier analyses, older adolescents $(\mathrm{HR}=1.20, p<.001)$, women $(\mathrm{HR}=1.64, p<.001)$, adolescents with higher levels of education $(\mathrm{HR}=2.09, p<.001)$, and from high SES families $(\mathrm{HR}=1.58, p<.001)$ were more likely to leave home earlier compared to men, adolescents with lower levels of education, and from low and middle SES families. In the third step (Model 3), gender interaction terms with all adolescentmother relationship variables were examined. As no interaction effects of adolescent gender and relationship quality were found to impact the timing of leaving home, we regard the second model as the final model.

\subsubsection{Adolescent-father relationship quality}

Three models concerning the relation between adolescent-father relationship quality and leaving home were examined (see Table 3). In Model 1, for every unit increase in warmth, the likelihood of leaving home decreased with $20 \%$ (HR $=0.80, p=.02$ ), while for every unit increase in paternal autonomy support, the likelihood of leaving home increased by $40 \%(\mathrm{HR}=1.40, p=.01)$. Moreover, for every unit increase in fathers' power, the likelihood of leaving home decreased with $13 \%$ (HR = 0.87, $p=.04)$. Conflict did not add to the prediction of the timing of leaving home. When the model was adjusted for covariates in the second step (Model 2), only paternal warmth remained as a significant predictor and all demographic covariates significantly contributed to the model. Again, older adolescents ( $\mathrm{HR}=1.25, p<.001)$, women ( $\mathrm{HR}=1.63, p<.001)$, adolescents with higher levels of education $(\mathrm{HR}=2.13, p<.001)$, and adolescents from high SES families $(\mathrm{HR}=1.69, p<.001)$ were more likely to leave home earlier. As a final step (Model 3), gender interaction terms were added to the model. A significant interaction of gender with conflict was found for father-adolescent relationship ( $\mathrm{HR}=1.41, p=.04)$. The effect of conflict with father on timing of leaving home was more pronounced for women compared to men. With higher levels of paternal conflict, the difference between men and women in the timing of leaving home became larger (see Fig. 2).

\section{Discussion}

This multiple cohort study examined how adolescents' perceived parental relationship quality predicted their timing of leaving home across six years, until they were approximately 21 years old, while controlling for adolescent's age, gender, education level and SES. Women compared to men, adolescents with higher levels of education compared to lower levels of education, and adolescents coming from high SES families compared to low-mid SES families were more likely to leave home earlier. Warmer relationship with parents and higher levels of power attributed to fathers, but not mothers, were associated with later timing of leaving home. In contrast, parents' higher autonomy support was associated with earlier timing of leaving home. Only for the father-daughter relationship, conflict predicted leaving home earlier. Although adolescents' demographic characteristics were more important predictors of leaving home than parental power and autonomy support, they did not explain the associations between parental warmth and the timing of leaving home. 
(a)

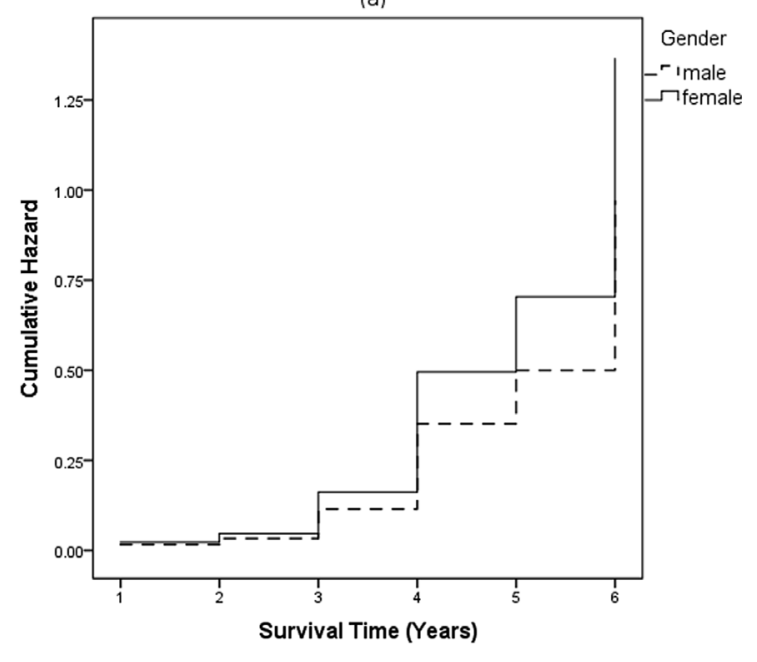

(b)

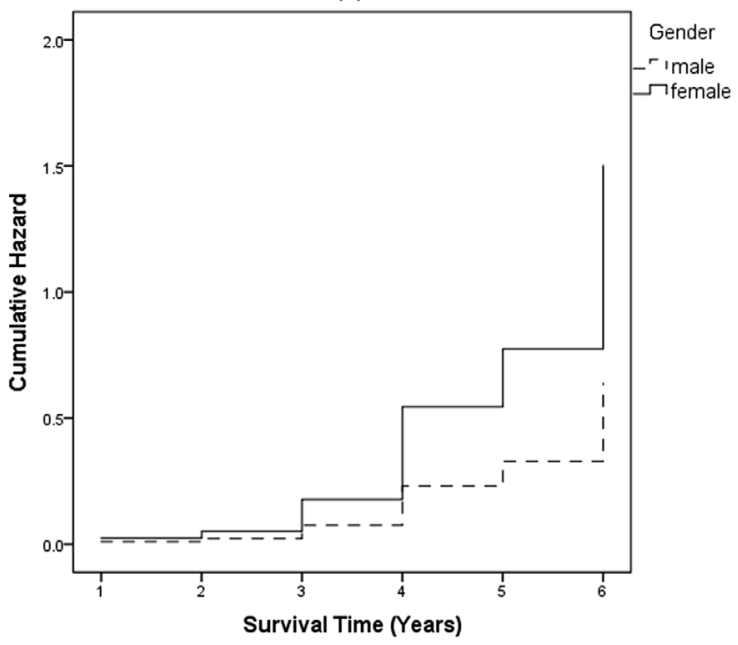

(c)

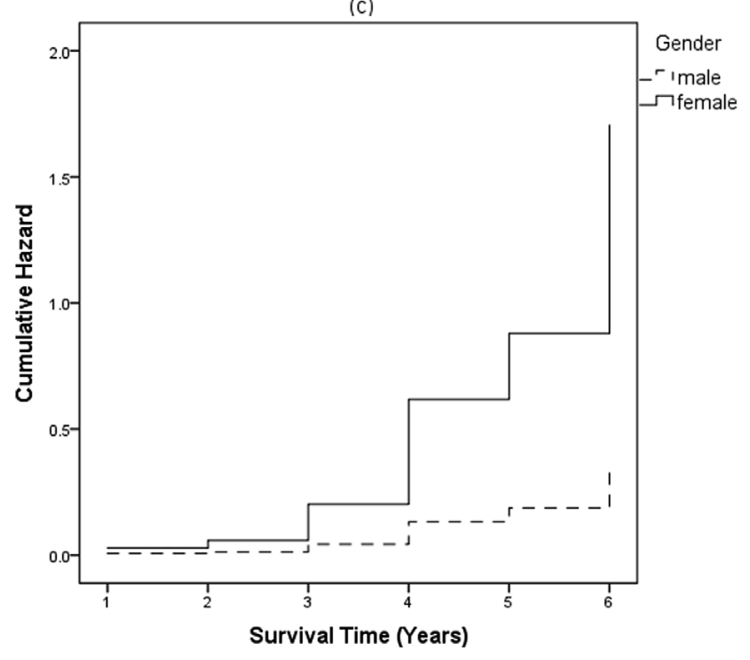

Fig. 2. Hazard (leaving home) functions of men and women based on (a) low, (b) medium, and (c) high levels of conflict with the father.

\subsection{Timing of leaving home explained by Adolescent's age, gender, education and SES}

Although the age of leaving home has increased during the last decades, half of our participants already left home during the course of the study. The mean age at which Dutch adolescents in the current sample left home was approximately 21 years, close to the mean age reported in a study with German adolescents (Seiffge-Krenke, 2006). As expected, timing of leaving home differed by gender, education level, and SES. Although previous findings on the effect of these demographic characteristics on the timing of leaving home have been inconsistent, this study supports research documenting that women, adolescents with higher education level and from families with higher SES move out earlier (De Jong Gierveld et al., 1991; De Marco \& Berzin, 2018). Among these demographic characteristics, education had the strongest association with the timing of leaving home, which may indicate moving out often co-occurs with starting higher education. Independent from adolescents' education, SES levels also predicted the timing of leaving home. Because we only used parents' highest education level as the indicator of family SES, we can only interpreted it as nonfinancial, cultural capital of the family. We can assume that parents with higher levels of education would be more supportive of their children pursuing higher education or other career-related opportunities than parents with lower levels of education. Furthermore, as education level is generally associated with occupational status and income, parents with high SES levels are expected to have more financial means to support the independent living of their children.

Although we chose survival analysis approach in calculating the mean age of leaving home and included adolescents who did not yet move out, the estimated age of leaving home was lower compared to recent statistics in the Netherlands (CBS, 2016). Because our sample contained relatively many adolescents from higher SES and education levels, and was predominantly Dutch, it is possible that the mean age of leaving home is higher in the general population. For instance, Kleinepier and De Valk (2017) reported that ethnic 
minorities in the Netherlands were less likely to leave home for independence compared to Dutch young individuals. Therefore, a more representative sample including ethnic minorities and more participants from low and middle SES families may result in a more accurate estimation for timing of leaving home.

\subsection{Parent-adolescent relationship predicts timing of leaving home}

In line with previous research (Seiffge-Krenke, 2006, 2009) and our hypotheses, the results showed that higher levels of parental warmth was related to later timing of leaving home, and higher levels of autonomy support was related to earlier timing of leaving home. The effects of warmth and autonomy support seemed to be slightly weaker for fathers than mothers and became less relevant for fathers when covariates were taken into account. Only the effects of parental warmth on the timing of leaving home were robust after including the demographic factors. Although warmth and autonomy support were positively correlated, these parenting characteristics had opposite effects on the timing of leaving home. We can argue that warmth and autonomy support have different functions but may co-occur as the autonomy-relatedness perspective suggests. Adolescents with autonomy supportive parents are more likely to be in a living situation they prefer (Kins, Beyers, Soenens, \& Vansteenkiste, 2009). On the other hand, adolescents who receive low levels of autonomy support may feel less ready to be independent, need more parental support and depend on their parents for longer period. In sum, these findings are in line with the autonomy-relatedness perspective and highlight that both perceived warmth and autonomy support are essential for young individuals' timing of leaving home. A parental relationship that balances warmth and autonomy support may be the key for a healthy and successful transition to adulthood by the adolescent in becoming self-reliant.

Contrary to our hypothesis and earlier research (Seiffge-Krenke, 2006), conflict with parents was not related to the timing of leaving home, except for the father-daughter relationship, as an interaction effect showed women were more likely than men to leave home earlier for higher levels of paternal conflict. Earlier studies showed conflict within family effected women more than men (Kalmijn, 2013), and women were more likely to continue to live at home when the relationship with the parents was perceived as positive (Blaauboer \& Mulder, 2010). Furthermore, women who left home earlier reported having a conflictual relationship with their mothers during adolescence (Stattin \& Magnusson, 1996). Thus, women seem to be more vulnerable to the effects of family conflict than men, yet our results showed no significant interaction effect between conflict with mother, gender and leaving home. Why we only found conflict with the father accelerates leaving home for women, needs further investigation. One possible explanation is that in our sample, mean conflict levels were low. Perhaps when more parent-adolescent relationship with medium-to-high levels of conflict is included, a significant association with timing of leaving home would be found. Furthermore, given that intergenerational conflict in ethnic minority families was related to earlier timing of leaving home (Lou, Lalonde, \& Giguère, 2012), conflict may still be an important factor in estimating the timing of leaving home, but needs to be further investigated within specific groups of adolescents.

Power attributed to parents was significantly related to the timing of leaving home only for father-adolescent relationships. For higher levels of paternal power, adolescents were more likely to leave home later. However, when controlled for demographics, paternal power was no longer an important predictor. Further analyses revealed this was only due to adolescent's SES. In our sample, adolescents from low and middle SES families perceived higher mean levels of paternal power compared to adolescents from high SES families. Therefore, it may be that adolescents from low and middle SES families delay leaving home due to higher levels of paternal power, but it is also possible that the effect of power on timing of leaving home is simply due to adolescents' SES. However, as the effect of paternal power were not robust, these results should be interpreted with caution.

\subsection{Strengths, limitations, and future research}

The present study has a number of strengths, such as the longitudinal design, the multiple parent-adolescent relationship characteristics investigated, and testing relationship qualities with mothers and fathers separately. However, several limitations need to be discussed. First, reasons for leaving home were not assessed, yet each parent-adolescent relationship characteristic may have a different role with respect to the timing of leaving home depending on the reasons for moving out. For instance, the parent-adolescent relationship quality may be a stronger predictor for moving out to live independently, rather than moving out for higher education. Second, the present study does not differentiate between those who moved to a semi-autonomous living situation (i.e. student dorms), or moved to live completely independent, or those who returned home, yet the effect of the parent-adolescent relationship quality on the timing of home leaving may be different for these groups. Third, only adolescents' perceptions of relationship qualities were included in our study. Often the most relevant picture of the relationship quality is provided by adolescents (Branje, van Aken, \& van Lieshout, 2002), yet parents as respondents may enhance our understanding of the relationship characteristics. Finally, our sample consisted predominantly of Dutch youth from mid-to-high SES families. Thus, our results cannot be generalized to all Dutch or Northern European families. Future research could benefit from addressing these limitations. In addition, adding a qualitative approach to the research design could increase our understanding of the association between parent-adolescent relationship characteristics and timing of leaving home with respect to reasons for moving out.

\section{Conclusion}

Our findings support the notion that family members are interconnected and that significant transitions in young individuals' lives are affected by the parent-child relationship quality. Parents' warmth, autonomy support, and -albeit less consistently - paternal 
power and conflict all affect the timing of leaving home. Since leaving home can be a potentially stressful time for both young individuals and their families, practitioners could benefit from a deeper understanding of the interaction between parents and adolescents during such significant life transitions. While a trend of delay in the timing of leaving home and other adulthood developmental tasks such as starting a career or getting married is being observed across industrialized countries, parents may be able to balance the warmth, autonomy support and power they provide during adolescence, in a way that stimulates the autonomy development of their child, so that they are sufficiently prepared for the transition to adulthood.

This research did not receive any specific grant from funding agencies in the public, commercial, or -not-for-profit sectors.

\section{Declaration of competing interest}

None.

\section{Acknowledgement}

RIA performed the statistical analyses, interpreted the data and drafted the manuscript. LDB interpreted the data and helped to draft the manuscript. WM participated in the design and coordination of the study, supervised data collection and provided feedback on the manuscript. SB participated in the design and coordination of the study, supervised data collection and critically revised the manuscript. All authors read and approved the final manuscript.

\section{Appendix}

Measurement Invariance Model Comparisons for Adolescent-Mother and Adolescent-Father Relationship Constructs

\begin{tabular}{|c|c|c|c|c|c|c|c|c|c|c|}
\hline \multirow[t]{2}{*}{ Measure } & \multicolumn{5}{|l|}{ Model Fit } & \multicolumn{5}{|c|}{ Model Comparisons } \\
\hline & $\chi^{2}$ & $d f$ & BIC & RMSEA & CFI & Models & $\Delta \chi^{2}(\Delta d f)$ & $\Delta \mathrm{BIC}$ & $\Delta$ RMSEA & $\Delta \mathrm{CFI}$ \\
\hline \multicolumn{11}{|l|}{ Warmth } \\
\hline M1. Configural & $1888.49^{*}$ & 103 & 38339.11 & 0.128 & 0.790 & & & & & \\
\hline M2. Configural ${ }^{1}$ & $797.47^{*}$ & 95 & 37304.00 & 0.083 & 0.918 & M2-M1 & $-1091.02(8) *$ & -1035.11 & -.045 & .128 \\
\hline M3. Metric & $867.72 *$ & 102 & 37325.00 & 0.084 & 0.910 & M3-M2 & $70.25(7)^{*}$ & 21.00 & .001 & -.008 \\
\hline M4. Scalar & $1111.52 *$ & 109 & 37520.35 & 0.093 & 0.883 & M4-M3 & $243.8(7)^{*}$ & 195.35 & .009 & -.027 \\
\hline \multicolumn{11}{|l|}{ Conflict } \\
\hline M1. Configural & $396.31 *$ & 53 & 20121.75 & 0.078 & 0.966 & & & & & \\
\hline M2.Metric & $401.53^{*}$ & 5 & 20092.13 & 0.075 & 0.966 & M2-M1 & $5.22(5)^{* *}$ & -29.62 & -.003 & .000 \\
\hline M3. Scalar & $409.38^{*}$ & 63 & 20065.14 & 0.072 & 0.966 & M3-M2 & $7.85(5)^{* *}$ & -26.99 & -.003 & .000 \\
\hline \multicolumn{11}{|l|}{ Power } \\
\hline M1. Configural & $808.67^{*}$ & 53 & 26235.03 & 0.116 & 0.901 & & & & & \\
\hline M2. Metric & 813.39* & 58 & 26204.91 & 0.111 & 0.901 & M2-M1 & $4.72(5)^{* *}$ & -30.12 & -.005 & .000 \\
\hline M3. Scalar & $843.84 *$ & 63 & 26200.53 & 0.108 & 0.898 & M3-M2 & $30.45(5)^{*}$ & -4.38 & -.003 & -.003 \\
\hline \multicolumn{11}{|l|}{ Aut. support } \\
\hline M1. Configural & $683.50 *$ & 76 & 20268.08 & 0.087 & 0.924 & & & & & \\
\hline M2. Metric & $694.22 *$ & 82 & 20234.00 & 0.084 & 0.923 & M2-M1 & $10.72(6)^{* *}$ & -34.08 & -.003 & -.001 \\
\hline M3. Scalar & $724.14 *$ & 88 & 20225.12 & 0.083 & 0.920 & M3-M2 & $29.92(6)^{*}$ & -8.88 & -.001 & -.003 \\
\hline
\end{tabular}

Note: BIC = Bayesian information criterion; RMSEA = root mean square error of approximation; CFI = comparative fit index; Aut. support = autonomy support.

${ }^{1}$ within-factor and across reporters error covariances were allowed; $* p<.001 ; * * p>.05$.

\section{References}

Aquilino, W. S. (2006). Family relationships and support systems in emerging adulthood. In J. J. Arnett, \& J. L. Tanner (Eds.). Emerging adults in America: Coming of age in the 21st century (pp. 193-217). Washington, DC, US: American Psychological Association.

Arnett, J. J. (2004). Adolescence and emerging adulthood: A cultural approach. Upper Saddle River, N.J: Pearson Prentice Hall.

Billari, F. C., \& Liefbroer, A. C. (2007). Should I stay or should I go? The impact of age norms on leaving home. Demography, 44, 181-198.

Blaauboer, M., \& Mulder, C. H. (2010). Gender differences in the impact of family background on leaving the parental home. Journal of Housing and the Built Environment, 25, 53-71.

Branje, S. J. T., van Aken, M. A. G., \& van Lieshout, C. F. M. (2002). Relational support in families with adolescents. Journal of Family Psychology, 16, 351-362.

Buck, N., \& Scott, J. (1993). She's leaving home: But why? An analysis of young people leaving the parental home. Journal of Marriage and Family, 55, 863-874.

Bucx, F., \& Van Wel, F. (2008). Parental bond and life course transitions from adolescence to young adulthood. Adolescence, 43, 71-88.

CBS (2016). Jongeren blijven langer bij ouders thuis [Young people stay at their parents' homes longer]. https://www.cbs.nl/nl-nl/nieuws/2016/27/jongeren-blijvenlanger-bij-ouders-thuis, Accessed date: 20 November 2019.

CBS (2018). 4\% of youth not in employment, education or training. https://www.cbs.nl/en-gb/news/2018/16/4-of-youth-not-in-employment-education-or-training, Accessed date: 20 November 2019.

CBS (2019). Mijlpalen twintigers schuiven op [Milestones in their twenties move up]. https://www.cbs.nl/nl-nl/nieuws/2019/20/mijlpalen-twintigers-schuiven-op, Accessed date: 20 November 2019.

Choroszewicz, M., \& Wolff, P. (2010). 51 million young EU adults lived with their parent(s) in 2008, Vol.50. Eurostat http://ec.europa.eu/eurostat/web/productsstatistics-in-focus/-/KS-SF-10-050?inheritRedirect=true, Accessed date: 15 October 2018. 
Coyette, C., Fiasse, I., Johansson, A., Montaigne, F., \& Strandell, H. (Eds.). (2015). Being young in Europe todayhttps://ec.europa.eu/eurostat/documents/3217494/ 6776245/KS-05-14-031-EN-N.pdf/18bee6f0-c181-457d-ba82-d77b314456b9, Accessed date: 20 November 2019.

Crocetti, E., \& Meeus, W. (2014). Family comes first!" Relationships with family and friends in Italian emerging adults. Journal of Adolescence, 37, $1463-1473$.

De Goede, I. H., Branje, S. J., Delsing, M. J., \& Meeus, W. H. (2009). Linkages over time between adolescents' relationships with parents and friends. Journal of Youth and Adolescence, 38, 1304-1315.

De Jong Gierveld, J., Liefbroer, A. C., \& Beekink, E. (1991). The effect of parental resources on patterns of leaving home among young adults in The Netherlands. European Sociological Review, 7, 55-71.

De Marco, A. C., \& Berzin, S. C. (2018). The influence of family economic status on home-leaving patterns during emerging adulthood. Families in Society: The Journal of Contemporary Social Services, 89, 208-218.

Elder, G. H., Johnson, M. K., \& Crosnoe, R. (2003). The emergence and development of life course theory. In J. T. Mortimer, \& M. J. Shanahan (Eds.). Handbook of the life course. New York: Kluwer Academic/Plenum Publishers.

Fry, R. (2016). For first time in modern era, living with parents edges out other living arrangements for 18- to 34-year-olds. Washington, D.C.: Pew Research Center (May). Furman, W., \& Buhrmester, D. (1985). Children's perceptions of the personal relationship in their social networks. Developmental Psychology, 21 , $1016-1024$.

Goldscheider, F., \& Goldscheider, C. (1994). Leaving and returning home in 20th century America Population. Bulletin, 48, 2-4.

Goldscheider, F., \& Goldscheider, C. (1998). The effects of childhood family structure on leaving and returning home. Journal of Marriage and Family, 60, 745-756.

Grotevant, H. D., \& Cooper, C. R. (1986). Individuation in family relationships: A perspective on individual differences in the development of identity and role-taking skill in adolescence. Human Development, 29, 82-100.

Güçlï, İ., \& Çetinkaya, N. (2015). Cox proportional hazards model in social science. International Journal of Social Sciences, 36, 63-74.

Kalmijn, M. (2013). Long-term effects of divorce on parent-child relationships: Within-family comparisons of fathers and mothers. European Sociological Review, 29, 888-898.

Kins, E., Beyers, W., Soenens, B., \& Vansteenkiste, M. (2009). Patterns of home leaving and subjective well-being in emerging adulthood: The role of motivational processes and parental autonomy support. Developmental Psychology, 45, 1416-1429.

Kins, E., De Mol, J., \& Beyers, W. (2013). "Why should I leave?" Belgian emerging adults' departure from home. Journal of Adolescent Research, 29 , 89-119.

Kins, E., Soenens, B., \& Beyers, W. (2013). Separation anxiety in families with emerging adults. Journal of Family Psychology, $27,495-505$.

Kleinepier, T., \& De Valk, H. A. D. (2017). Leaving home of migrant and Dutch young adults: Parent-child and peer relations. Journal of Comparative Family Studies, 48, 15-39.

Le Blanc, D., \& Wolff, F. C. (2006). Leaving home in Europe: The role of parents' and children's incomes. Review of Economics of the Household, 4, 53-73.

Little, T. D. (2013). Methodology in the social sciences. Longitudinal structural equation modeling. New York, NY, US: Guilford Press.

Lou, E., Lalonde, R. N., \& Giguère, B. (2012). Making the decision to move out. Journal of Cross-Cultural Psychology, 43, 663-670.

Meeus, W. H. J., Akse, J., Branje, S. J. T., Ter Bogt, T., Delsing, M., Van Doorn, M. D., et al. (2004). Codebook of the research project conflict and management of relationships (CONAMORE). The Netherlands: Utrecht University Unpublished manuscript.

O'Connor, T. G., Allen, J. P., Bell, K. L., \& Hauser, S. T. (1996). Adolescent-parent relationships and leaving home in young adulthood. New Directions for Child Development, 71, 39-52.

Seiffge-Krenke, I. (2006). Leaving home or still in the nest? Parent-child relationships and psychological health as predictors of different leaving home patterns. Developmental Psychology, 42, 864-876.

Seiffge-Krenke, I. (2009). Leaving-home patterns in emerging adults. European Psychologist, 14, 238-248.

Seiffge-Krenke, I. (2010). Predicting the timing of leaving home and related developmental tasks: Parents' and children's perspectives. Journal of Social and Personal Relationships, 27, 495-518.

Seiffge-Krenke, I. (2013). "She's leaving home ..." Antecedents, consequences, and cultural patterns in the leaving home process. Emerging Adulthood, 1, 114-124.

Shulman, S., Laursen, B., Kalman, Z., \& Karpovsky, S. (1997). Adolescent intimacy revisited. Journal of Youth and Adolescence, $26,597-617$.

South, S. J., \& Lei, L. (2015). Failures-to-launch and boomerang kids: Contemporary determinants of leaving and returning to the parental home. Social Forces, 94, $863-890$.

Stattin, H., \& Magnusson, C. (1996). Leaving home at an early age among females. New Directions for Child Development, 71, 53-69.

Tang, S. (1997). The timing of home leaving: A comparison of early, on-time, and late home leavers. Journal of Youth and Adolescence, $26,13-23$. 